\title{
Nanotechnology applications in osteodistraction
}

\author{
Adam E. Singleton', Jon P. Ver Halen ${ }^{2,3,4}$ \\ ${ }^{1}$ Department of Otolaryngology-Head and Neck Surgery, University of Tennessee Health Science Center, Memphis, TN 38163, USA. \\ ${ }^{2}$ Division of Plastic, Reconstructive, and Hand Surgery, Baptist Memorial Healthcare Corporation, Memphis, TN 38120, USA. \\ ${ }^{3}$ Vanderbilt Ingram Cancer Center, Nashville, TN 37232, USA. \\ ${ }^{4}$ St Jude Children's Research Hospital, Memphis, TN 38105, USA.
}

Address for correspondence: Dr. Jon P. Ver Halen, Division of Plastic, Reconstructive, and Hand Surgery, Baptist Memorial Healthcare Corporation, Memphis, TN 38120, USA. E-mail: jpverhalen@gmail.com

\begin{abstract}
Most current strategies for bone regeneration have relatively satisfactory results. However, there are drawbacks and limitations associated with their use and availability, and even controversial reports about their efficacy and cost-effectiveness. The induction of new bone formation through distraction osteogenesis (DO) is widespread clinical application in the treatment of bone defects, limb deformities, and fracture nonunions. However, a lengthy period of external fixation is usually needed to allow the new bone to consolidate, and complications such as refracture at the distraction gap often occur. Although various biomaterials have been used as injectable delivery systems in DO models, little has been reported on the use of nanobiomaterials as carrier materials for the sustained release of growth factors in bone regeneration. One area of focus in nanotechnology is the delivery of osteogenic factors in an attempt to modulate the formation of bone. This review article seeks to demonstrate the potential of nanobiomaterials to improve biological applications pertinent to osteodistraction.
\end{abstract}

Key words:

Bone regeneration, distraction osteogenesis, nanobiomaterials, nanoparticles, nanotechnology

\section{INTRODUCTION}

The most common form of bone regeneration is fracture healing, during which the pathway of normal fetal skeletogenesis is reactivated..$^{[1]}$ However, with substantial loss of bone tissue the regenerative process is compromised, as is seen in cases of avascular necrosis and osteoporosis. These challenging situations often necessitate the augmentation of natural bone repair.

Distraction osteogenesis (DO) is a method of producing

\begin{tabular}{|l|l|}
\hline \multicolumn{2}{|c|}{ Access this article online } \\
\hline Quick Response Code: & Website: \\
\hline & www.parjournal.net \\
\cline { 2 - 3 } & \\
\hline
\end{tabular}

large quantities of bone using local host tissues stimulated by mechanical distraction forces. After an osteotomy the continuously enlarging gap is filled with living bone via intramembranous ossification of the newly built bone. ${ }^{[2]}$ The main advantage of DO is that it can achieve regeneration of living bone with the same strength and width as that of the native bone. Peripheral nerves, vessels, muscles, tendons, ligaments, and skin are also gradually lengthened in proportion to the lengthening bone. ${ }^{[3]}$ DO has been widely used for the treatment of leg-length discrepancy, nonunion, traumatic bone defect, deformity, musculoskeletal tumor and osteomyelitis. ${ }^{[4]}$

Recent discoveries have highlighted that nanotechnology may universally augment all materials used for regrowing bone. ${ }^{[5]}$ Nanotechnology, a new focus in the area of biomedical research, involves the visualization, manipulation, and fabrication of materials on the smallest scales, in dimensions of $1 \mu \mathrm{m}$ down to $10 \AA$. The unique feature of this nanotechnological approach is that it enables 
consideration of the spatial and temporal levels of material organization in order to develop appropriate hierarchical structures. These nanomaterials have shown superior properties over their conventional counterparts owing to their distinctive nanoscale features and novel physical properties. $^{[6-8]}$ Currently, applications of nanomaterials in osteodistraction include the use of nanofilms and nanoparticles to protect against infection in surgical implants, and the use of engineered surfaces to improve bone healing and formation and to assist in osteogenesis via the distribution of osteogenic factors. This review seeks to demonstrate the potential of nanobiomaterials to augment biological applications pertinent to osteodistraction.

\section{NANOFEATURES INFLUENCE CELL BEHAVIOR}

The topography of nanomaterials (e.g. pores, ridges, grooves, fibers, nodes, and combinations of these features) is known to significantly influence cell behavior. ${ }^{[9]}$

Furthermore, implant surface chemistry plays a critical role in deciding the performance and success of these devices. The interaction of four proteins - fibronectin, vitronectin, laminin, and collagen - is known to enhance osteoblast function on nanomaterials compared to conventional materials. ${ }^{[10]}$ Proteins and other biomolecules that dynamically adsorb to biomaterial surfaces upon implantation can trigger nonspecific inflammatory responses, which can limit integration of the device and influence in vivo performance.

The wettability of a nanomaterial can significantly alter cell behavior. The surface composition, surface treatment, surface roughness, immobilization of various chemical agents to the surface of the implant or biomaterial, and the presence of nanofeatures on the surface, alter surface wettability and affect cell behavior. ${ }^{[9]}$ Increased surface wettability, or hydrophilicity, has been associated with enhanced protein adsorption, and consequently, cell adhesion on biomaterials. The ability to synthesize and process nanomaterials with tailored structures and topographies to direct subsequent functions of specific cell lines provides potential for the design of novel proactive biomaterials that could improve the efficacy of bone implants.

\section{OSTEODISTRACTION AND NANOTECHNOLOGY}

Although DO with an external fixator has become a popular method of treating cases with substantial bone loss, it is not without complications [Figure 1]. One of the major drawbacks of this method is that it is time-consuming and the ring fixator must be maintained in situ until full consolidation of the bone. This is inconvenient and even uncomfortable for the patient. ${ }^{[11]}$

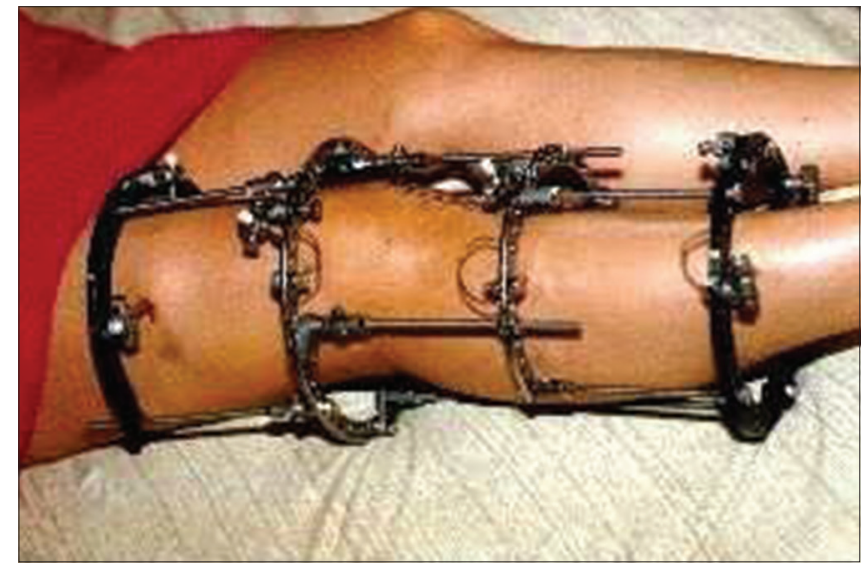

Figure 1: Ilizarov's external ring fixator for limb lengthening

Further, Paley ${ }^{[12]}$ reported pin tract infections in $36 \%$ of patients, and Karger et al. ${ }^{[13]}$ noted joint contractures in $65 \%$ of patients when the limb was lengthened by $24 \%(7 \mathrm{~cm})$ of its initial length.

Advances in nanotechnology have stimulated investigations into cell-substrate interactions from the microscale to the nanoscale. Using this technique, it is now possible to fabricate advanced materials with more favorable properties for orthopedic applications. There have been quite a few reports in the literature investigating the usefulness of various nanomaterials for reducing the risk of implant-associated infections and accelerating the bone healing process.

\section{NANOCOMPOSITES FOR BONETISSUE REGENERATION}

The introduction of polymer nanocomposites into bone tissue engineering allows the complex architecture of native bone tissue to be mimicked, providing a novel and practical approach to the massive production of materials for bone tissue engineering..$^{[8]}$ Synthetic or natural polymer matrices offer a wide range of mechanical properties and exhibit different biodegradation features, whereas various inorganic nanoparticles provide bioactivity. Furthermore, their integration makes it possible to fabricate materials that mimic the structural and morphological organization of native bone. Although there is great potential to improve current biomaterials and develop advanced nanocomposite scaffolds for bone regeneration, each of these materials has specific drawbacks.

Bioceramic/synthetic polymer nanocomposites for bone regeneration

Nanocomposites based on bioceramics and biodegradable polymers (e.g. calcium phosphate, calcium sulfate, beta-tricalcium phosphate [ $\beta$-TCP], hydroxyapatite [HA], poly-lactic acid [PLA], poly-glycolic acid, and poly-lactide-co-glycolide) have attracted much attention 
for bone tissue regeneration because of the excellent combination of bioactivity and osteoconductivity of bioceramics with the flexibility and shape controllability of polymers. Such nanocomposites are also able to closely mimic the microstructure of bone. These composites have shown a better cell response than conventional composites, depending on different factors, such as material composition, fabrication method, microstructure and mechanical properties of the composites, among others. Nonbiodegradable polymers have been used in bone tissue engineering for their better mechanical properties and chemical stability than biodegradable polymers. However, some of these polymers, such as polyethylene, polypropylene and poly (etherether ketone), demonstrate severe immune responses.

\section{Bioceramic/natural polymer nanocomposites for bone regeneration}

Natural biopolymers (e.g. chitosan, collagen, HA, silk fibroin, and calcium phosphate) are currently of interest in tissue engineering because their biological recognition may positively support cell adhesion and function. However, these polymers have poor mechanical properties. HA-reinforced natural polymers exhibit much better mechanical and biological properties, and thus may resolve many of these difficulties.

\section{Carbon nanotube/polymer nanocomposites for bone regeneration}

Carbon nanotubes (CNTs) have excellent mechanical properties, a highly specific surface area and a low density, which makes them ideal for the fabrication of tissue engineering scaffolds with polymers. The addition of CNTs to a polymer helps cell growth and promotes cell attachment, proliferation and differentiation. The cytotoxicity of CNTs is still obscure, but their toxicity can be reduced when incorporated into a polymeric matrix, thus making it possible to fabricate CNT - polymer nanocomposites for bone tissue engineering. However, the long-term toxicity of CNTs in human tissue and their influence on bone remodeling need further investigation.

\section{IMPLANT-ASSOCIATED INFECTION AND NANOTECHNOLOGY}

Implant-associated infection is one of the most serious complications in orthopedic surgery. Bone infections associated with foreign body materials are especially difficult to treat. Removal of the infected implants, long-term systemic antibiotic therapy, and multiple revisions with radical debridement are frequently required..$^{[14-16]}$ The consequences of infection can be devastating and may lead to prolonged hospitalization, poor functional outcome, sepsis, and even amputation. ${ }^{[17]}$

Implant-associated infections are the result of bacterial adhesion to an implant surface and subsequent biofilm formation at the implantation site. ${ }^{[18]}$ The formation of biofilm takes place in several stages, starting with rapid surface attachment, followed by multilayered cellular proliferation and intercellular adhesion in an extracellular polysaccharide matrix. ${ }^{[19]}$ Biofilms are resistant to both the immune response and systemic antibiotic therapies.

Different surface modification strategies for orthopedic implants have been investigated, including (a) the addition of materials with desired functions to the surface; (b) the conversion of the existing surface into more desirable chemistries and/or topographies; and (c) the removal of material from the existing surface to create new relevant topographies. ${ }^{[20]}$ The latter, which was tested during in vitro studies, provides the surface with a specific roughness to promote osteoblast proliferation and cell adhesion.

Coating metal implants with a bactericidal film would inhibit bacteria from colonizing implant surfaces and provide a high antibiotic concentration in a local region commonly known as a nidus for bacterial infection. ${ }^{21]}$ Different surface modifications and coating techniques can be used, such as direct impregnation with antibiotics and immobilization of an antimicrobial agent in a matrix capable of binding to different surfaces, ${ }^{[22]}$ as well as coating with antimicrobial, active metals such as copper and silver, ${ }^{[23]}$ nitric oxide-releasing materials ${ }^{[24]}$ and titanium dioxide films. ${ }^{[25]}$

Ainslie et al. ${ }^{[26]}$ have shown in vitro that nanostructured surfaces display reduced inflammation in comparison with a respective flat control. Controlled drug release from the surfaces of implanted medical devices coated with nanostructured films is expected to yield additional advantages over conventional coatings. However, so far this approach has gained limited clinical use for orthopedic coatings.

Li et al..$^{[21]}$ developed biodegradable polypeptide multilayer nanofilms to potentially serve as antibiotic carriers at the implant-tissue interface. They demonstrated that polypeptide multilayer nanofilms, with or without cefazolin, have antibacterial activity against organisms frequently associated with osteomyelitis, and may improve bone healing through improving osteoblast cell adhesion, viability, and proliferation.

Etienne et al..$^{[27]}$ developed a strategy based on the insertion of an antimicrobial peptide (defensin) into polyelectrolyte multilayer films built by the alternate deposition of polyanions and polycations. Examination of Escherichia coli D22 growth at the surface of defensin-functionalized films revealed 98\% inhibition when positively charged poly (l-lysine) was the outermost layer of the film, owing to the interaction of the bacteria with the positively charged ends of the film.

Diamond nanoparticles or nanodiamonds (ND) have recently gained significant attention for local drug release 
in the form of coatings. Recent studies of cell viability, such as the production of luminescent adenosine 5' triphosphate, have shown that ND are not toxic to a variety of cell types. ${ }^{[28]}$ Huang et al. ${ }^{[29]}$ have examined the cytotoxicity and anti-inflammatory response of dexamethasone-loaded ND nanofilms in vivo and found that the nanofilms are non-apoptotic and non-cytotoxic, with efficient drug-eluting characteristics, thus being of great interest as novel implant coatings.

Rauschmann et al. ${ }^{[30]}$ have developed a bioresorbable composite of calcium sulfate and nanoparticulate HA for the local delivery of antibiotics to tackle bone infection. No in vitro cytotoxicity was noticed, and the composite material exhibited better biocompatibility than pure calcium phosphate. Owing to its high porosity, it revealed initial high antibiotic release followed by a subsequent decline, ensuring concentrations well above the respective minimal inhibition concentrations of gentamicin- and vancomyin-susceptible bacteria within the first 3-4 days.

Adams et al. ${ }^{[31]}$ have examined the release of vancomycin from thin sol-gel films deposited on titanium alloy surfaces implanted in an animal model. The coatings exhibited a significant inhibiting effect against the adhesion and biofilm formation of Staphylococcus aureus.

Active coatings for the delivery of therapeutic molecules using the advantages of nanotechnology have a bright future. Implant-related microbial infection is a serious threat after orthopedic surgery. The literature review has revealed that an increasing volume of research is focusing on developing antimicrobial agents with high efficiency and controlled-release ability. This method is very efficient because it reduces systemic toxicity and the side-effects of parenteral antibiotics, while also yielding higher drug concentrations in the relevant tissues.

\section{THE BONE HEALING PROCESS AND NANOTECHNOLOGY}

Surfaces that contain micro- and nanoscale features in a well-controlled, "engineered" manner significantly affect cellular and subcellular function. The optimal micro/ nanostructure for desired osseointegration is still a subject of debate.

A number of novel approaches have been developed for the fabrication of biomaterial-based three-dimensional scaffolds. ${ }^{[32]}$ The electrospinning method has been actively explored recently and offers ultrafine polymer fibers, a high specific surface area, and the possibility of various modifications, including mineralization of scaffolding with HA, which has been shown to reduce cellular cytotoxicity in vitro. ${ }^{[33,34]}$ The features of nanofiber mats are morphologically similar to those of the extracellular matrix of natural tissue.
The development of nanofibers has enhanced the scope of fabricating scaffolds to mimic the architecture of natural human tissues at nanoscale. The high porosity of nanofiber scaffolds provides more structural space for cell accommodation and facilitates the efficient exchange of nutrients and metabolic waste between a scaffold and its environment.

A crucial point for the success of a scaffold, especially in bone tissue engineering, is a combination of the structural/mechanical properties of a polymer structure and biological activity, both of which play a critical role in cell seeding, proliferation, and new tissue formation. The interest in temporary substitutes is that they provide mechanical support until the tissue has regenerated and remodeled itself naturally.

Kikuchi et al. ${ }^{[35]}$ fabricated an artificial bone material having a bone-like nanostructure and chemical composition. Composed of HA and collagen, the bone material was synthesized under biomimetic conditions through self-organization mechanisms between HA and collagen. The nanofibrous architecture improved the features of protein adsorption, including serum fibronectin and vitronectin, which may mediate cell interactions with scaffolds. ${ }^{[36]}$

Recombinant human bone morphogenetic protein (rhBMP) is used to induce ectopic bone formation in skeletal and nonskeletal sites. ${ }^{|37|}$ Many other carriers have already been reported: $\beta$-TCP, biphasic calcium phosphate, ceramics, insoluble bone matrix, collagen, PLA-polyglycolic acid copolymer, tantalum, and titanium. ${ }^{[38-42]}$ Most carriers loaded with BMP-2 show an early burst of BMP-2 release with a reduction in retained BMP-2 to less than $10 \%$ within the first 5 days.

Previous studies, using the rabbit model of DO, have shown that the optimal rate of lengthening is $0.7 \mathrm{~mm} /$ day, twice-daily lengthening ${ }^{\mid[3]}$ when lengthened faster $(>1.3 \mathrm{~mm} / \mathrm{day})$ the quality of the regenerated bone is poor. Al Ruhaimi ${ }^{[44]}$ suggested that shortening the duration of osteodistraction by increasing the distraction rate is unsuccessful and results in nonunion. Increasing the distraction rate together with the local application of drugs to the distraction site is an evolving area. ${ }^{\mid 45]}$ Local application of osteogenic mediators such as BMPs into the distraction site is useful; ${ }^{[45]}$ however, targeting and transcutaneous injections are current problems after initiation of the distraction.

Wang et al. ${ }^{[46]}$ used a rabbit model of a $1 \mathrm{~cm}$ tibial bone defect to study biomaterials in DO, to determine whether this could reduce the treatment time and enhance the quality of bone formation. According to their results, the combination of biomaterials with a DO technique could be a new and cost-effective means to reduce treatment time and enhance bone consolidation in the management of larger bone defects. 
BMP-2 and BMP-7 have also been reported to promote bone consolidation during DO. ${ }^{[4]}$ Therefore, exogenous administration of BMP may enhance DO both temporally and spatially and enable rapid distraction, thereby shortening the time to repair the bone defect. Although various biomaterials have been used as injectable delivery systems in DO models, little has been reported on the use of nanobiomaterials as carrier materials for the sustained release of growth factors in bone regeneration.

The most widely explored osteogenic factors are the members of the transforming BMP-2 family, which have all been shown to augment the bone-forming capacity of osteoblastic cell populations when delivered at the appropriate times in the wound-healing cascade. ${ }^{[48]}$ Unfortunately, these factors have been shown to be a challenge to formulate and deliver, owing to their complex tertiary structures, short biological half-lives, and possible systemic toxicity.

Efficient delivery of the osteogenic molecules in vivo can be achieved by incorporating them into a carrier, which can be implanted directly into the defect site. This method results in localized drug delivery and reduces possible toxic systemic effects. Synthetic polymers are attractive for this application as they can be fabricated to exact specifications, allowing for the fine-tuning of the physical properties that influence drug release, as well as their rate of degradation. For controlled release, osteogenic factors can be incorporated directly into the polymer component of poly-hydroxy acid matrices through a number of techniques, ${ }^{[49]}$ and their final release can be modulated by parameters such as pore size and protein loading of the matrix..$^{[50]}$

Haidar et al..$^{[50]}$ studied the effect of an early single injection of biodegradable core-shell nanoparticles loaded with various low doses of recombinant human BMP-7 (rhBMP-7/rhOP-1) on new bone regeneration and consolidation in a rabbit model of tibial DO. According to their results, the use of nanoparticles maintains the bioactivity of the encapsulant, minimizes the therapeutic doses of rhOP-1, and accelerates DO via its localized release-controlled osteogenic, and naturally biocompatible polymeric properties.

Elimination of the external frame distraction device can itself improve the results of osteodistraction [Figures 2-5]. Konaş et al..$^{[51]}$ developed an internal distractor that allows local intermittent BMP-2-containing chitosan hydrogel infusion to the distraction site during distraction. According to their results, distraction with an osteoinductive drug-releasing distractor can increase ossification in DO. Moreover, chitosan is biocompatible, and its particles act as bony extracellular matrix elements and integrate with the tissue. In the authors' own experience, chitosan-alginate scaffolds were superior to

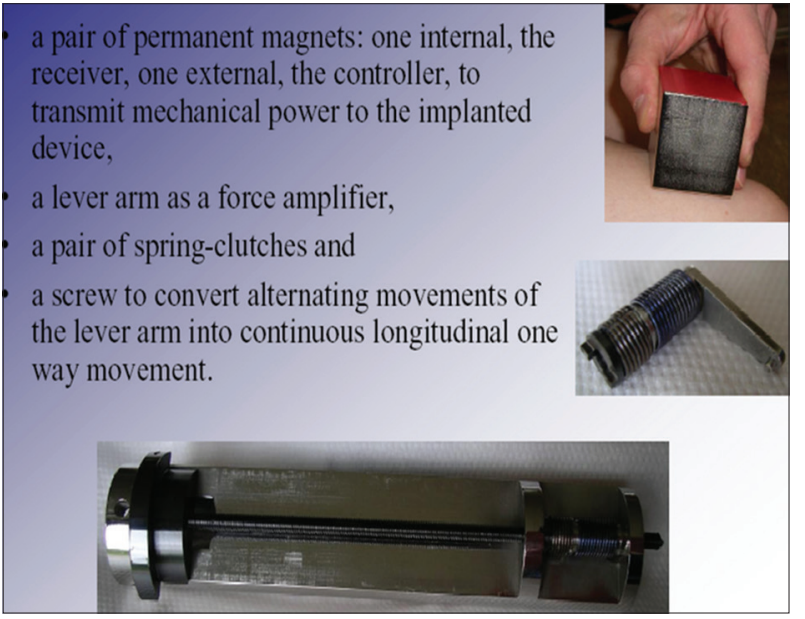

Figure 2: The Phenix M-Bone device consists of a pair of permanent magnets (one external, the controller, and one internal, the receiver, which transmit mechanical power to the implanted device) upper figure: the controller magnet; middle figure: a lever arm as a force amplifier; lower figure: a screw to convert alternating movements of the lever arm into continuous longitudinal one-way movements

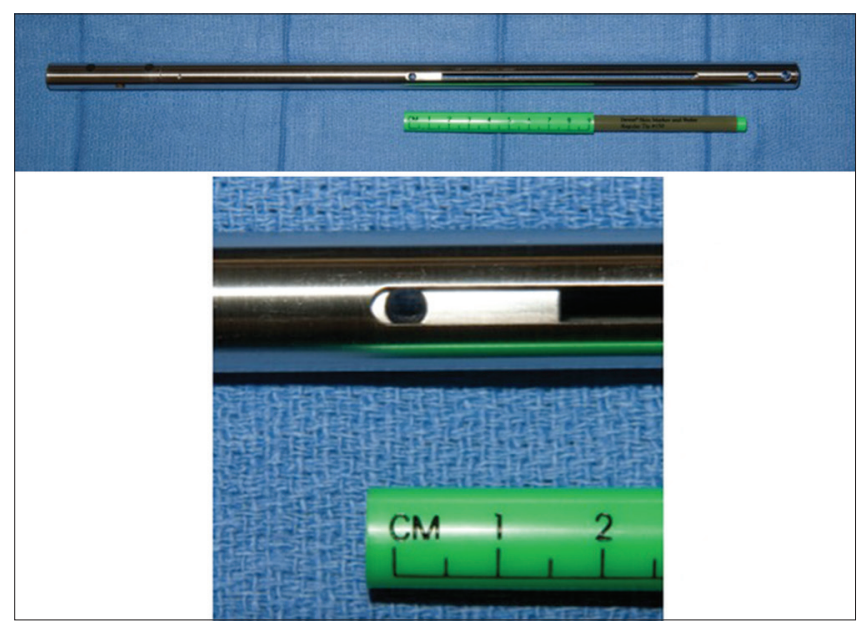

Figure 3: Photograph of the Phenix-M bone transport rod (above). Closeup of bone transport mechanism, with threaded core used to transfix the bone transport segment (below)

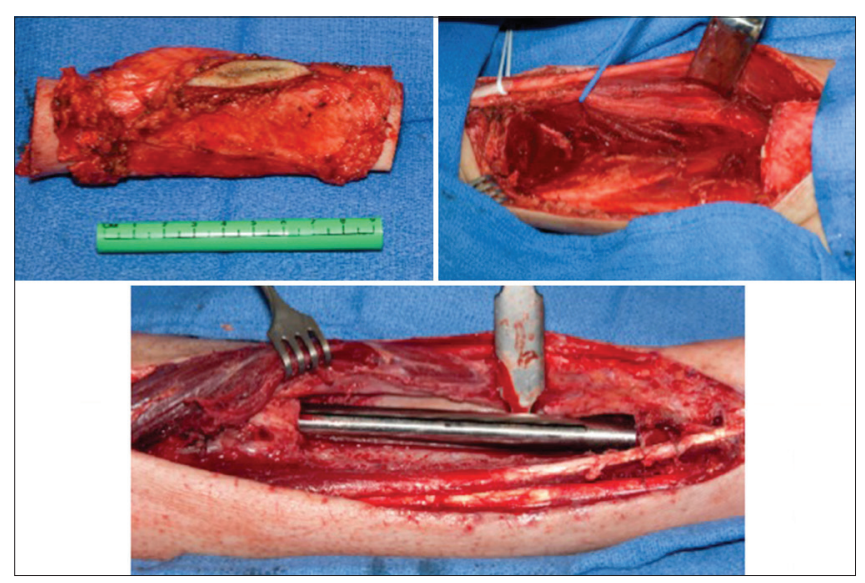

Figure 4: A 15-year-old boy presented with osteosarcoma of the distal tibia. Surgical resection specimen (above, left). Surgical defect after resection (above, right). Bone transport device, after implantation (below). The bone transport segment can be identified in the left of the figure 


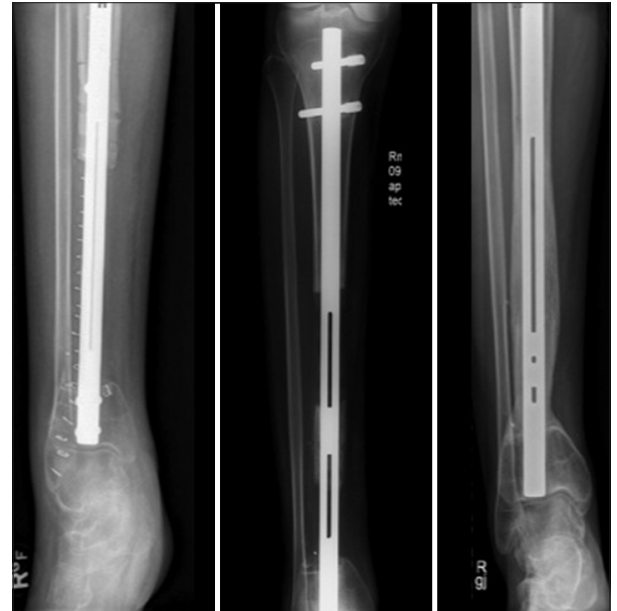

Figure 5: A 15-year-old boy presented with osteosarcoma of the distal tibia. Radiographs demonstrate initial resection and the placing of the bone transport device (left), midpoint of transport (middle), and after bony consolidation (right)

no treatment for the healing of critical calvarial defects in a rat model. Adding BMP-2 to these scaffolds further improved bone regeneration, in both a rat and a clinical model (data not shown).

\section{OSTEODISTRACTION AND NANOTECHNOLOGY DRUG- RELEASE SYSTEMS}

One area of focus in nanotechnology is the delivery of osteogenic factors in an attempt to modulate the formation of bone. Research has focused on the use of biodegradable materials as scaffolds for cellular ingrowth, cell transplantation, or the delivery of therapeutic molecules as methods for regenerating osseous tissue.

Since Urist et al..$^{[52]}$ demonstrated that glycoproteins extracted from demineralized rabbit could induce bone formation in ectopic sites in tibia matrix from rabbits and mice, tremendous advances have been made in the development of recombinant growth factors, proteins, and peptides for the regeneration of bone tissue. These factors have been shown to induce bone formation within a defect without the use of a carrier, but their relatively short half-lives necessitate the use of significant amounts of protein.

To increase the in vivo efficacy as well as reduce the quantities needed, the development of carriers capable of controlled, sustained delivery of proteins and peptides is desirable. In order to minimize surgical intervention for the implantation of controlled-release scaffolds, the development of materials that can be injected and cross-linked in situ would be desirable.

DO is characterized by the formation of new bone between two osteotomized bone segments, which are separated by gradual traction. The consolidation period represents the time needed for a complete bridging of the distraction gap by bone and a further maturation of this bone. In general, the bone consolidation phase takes approximately 6-12 weeks in the craniomaxillofacial region and 3-6 months in long bones. ${ }^{\mid 53]}$

Various methods have been tested to promote bone formation in the distraction gap, e.g. electrical and mechanical stimulation, ${ }^{[54]}$ transplantation of osteoblast-like cells, ${ }^{[55]}$ administration of growth factors such as bone morphogenetic proteins, or fibroblast growth factor 2. ${ }^{[56]}$ Another procedure to accelerate bone regeneration involves the application of osteogenic proteins in the distraction gap using nanotechnology-fabricated drug-release systems. ${ }^{\text {[57] }}$

Much research effort has been committed to the investigation of ordered mesoporous silica materials in the biomedical field for two main reasons: their ability to regenerate bone tissue ${ }^{[58]}$ and their drug delivery possibilities. ${ }^{[59]}$ When these silica-based ordered mesoporous materials are exposed to the physiological environment, a series of chemical reactions take place in the material-living tissue interface, which lead to incorporation of the material into the living tissue.

Available pore volume and surface play a key role in the protein-loading capacity of silica-based ordered mesoporous materials. If large biomolecules, such as certain proteins, are targeted to be adsorbed in ordered mesoporous materials, these matrices should present several characteristics: (1) a large size pore size to allow diffusion; (2) a large surface area to allow a large retention percentage; (3) and a high pore volume to offer available space into the mesopores to be filled by the protein.

Several natural and synthetic polymers have been explored for use as delivery vehicles for bone-inductive molecules. The poly ( $\alpha$-hydroxy acid) family of polymers, including PLA, poly (lactic-co-glycolic acid) (PLGA), and their copolymers, have been the focus of much of this research as they are biocompatible, undergo controllable hydrolytic degradation into natural metabolites, and can be processed into many forms. ${ }^{[60]}$ In addition, microparticles of PLA and PLGA have been used to deliver many factors, including transforming growth factor 1 and BMP-2, into osseous defects. ${ }^{[61]}$ Finally, porous PLGA scaffolds have also been developed to provide support for cellular migration. Some of this work focused on the adsorption of therapeutic agents onto prefabricated scaffolds, but control of the factor's release kinetics was found to be limited with this technique.

\section{FUTURE CHALLENGES}

Bone growth and remodeling involves a plethora of growth factors, recruitment of mesenchymal stem cells, and the action of three different mature cell types (osteoblasts, 
osteocytes and osteoclasts) as well other factors that are yet to be revealed. To move to the next developmental phase of nanobiomaterials science, it is critical to understand the cellular and molecular basis governing the interaction between nanostructure and cells.

It has become more apparent that nanomaterials hold much promise for bone regeneration applications, and this warrants further exploration. The endpoint is limited only by the extent of our imaginations.

\section{REFERENCES}

I. Ferguson C, Alpern E, Miclau T, Helms JA. Does adult fracture repair recapitulate embryonic skeletal formation? Mech Dev 1999;87:57-66.

2. Aronson J, Harrison BH, Stewart CL, Harp JH Jr. The histology of distraction osteogenesis using different external fixators. Clin Orthop Relat Res 1989;(24I):106-16.

3. Tsuchiya $\mathrm{H}$, Tomita K. Distraction osteogenesis for treatment of bone loss in the lower extremity.J Orthop Sci 2003;8: I 16-24.

4. Tsuchiya H, Tomita K, Minematsu K, Mori Y, Asada N, Kitano S. Limb salvage using distraction osteogenesis. A classification of the technique. J Bone Joint Surg Br 1997;79:403-II.

5. Tran N,Webster TJ. Nanotechnology for bone materials. Wiley Interdiscip Rev Nanomed Nanobiotechnol 2009; I:336-5I.

6. WebsterTJ, Siegel RW, Bizios R. Osteoblast adhesion on nanophase ceramics. Biomaterials 1999;20:1221-7.

7. Webster TJ, Ergun C, Doremus RH, Siegel RW, Bizios R. Enhanced functions of osteoblasts on nanophase ceramics. Biomaterials 2000;21:1803-10.

8. Sahoo NG, Pan YZ, Li L, He CB. Nanocomposites for bone tissue regeneration. Nanomedicine (Lond) 2013;8:639-53.

9. Laurencin CT, Kumbar SG, Nukavarapu SP. Nanotechnology and orthopedics: a personal perspective. Wiley Interdiscip Rev Nanomed Nanobiotechnol 2009;1:6-10.

10. Christenson EM, Anseth KS, van den Beucken JJ, Chan CK, Ercan B, Jansen JA, Laurencin CT, Li WJ, Murugan R, Nair LS, Ramakrishna S, Tuan RS, Webster T], Mikos AG. Nanobiomaterial applications in orthopedics.J Orthop Res 2007;25: I I-22.

II. Kim SJ,MandarA, Song SH, Song HR. Pitfalls of lengthening over an intramedullary nail in tibia: a consecutive case series. Arch Orthop Trauma Surg 20। 2; I32: I85-9I.

12. Paley D. Problems, obstacles, and complications of limb lengthening by the Ilizarov technique. Clin Orthop Relat Res 1990;(250):8I-104.

13. Karger C, Guille JT, Bowen JR. Lengthening of congenital lower limb deficiencies. Clin Orthop Relat Res 1993;291:236-45.

14. Darouiche RO. Treatment of infections associated with surgical implants. N Engl J Med 2004;350:1422-9.

15. Anderson JM. Biological responses to materials. Ann Rev Mater Res 2001;31:81-II0.

16. An YH, Friedman RJ. Prevention of sepsis in total joint arthroplasty. J Hosp Infect 1996;33:93-108.

17. Calhoun JH, Manring MM. Adult osteomyelitis. Infect Dis Clin North Am 2005; 19:765-86.

18. Zilberman M, Elsner JJ. Antibiotic-eluting medical devices for various applications.J Control Release 2008;130:202-I5.

19. Trampuz A, Osmon DR, Hanssen AD, Steckelberg JM, Patel R. Molecular and antibiofilm approaches to prosthetic joint infection. Clin Orthop Relat Res 2003;(4I4):69-88.

20. Duan K, Wang R. Surface modifications of bone implants through wet chemistry.J Mater Chem 2006;16:2309-2I.

2I. Li H, Ogle H, Jiang B, Hagar M, Li B. Cefazolin embedded biodegradable polypeptide nanofilms promising for infection prevention: a preliminary study on cell responses.J Orthop Res 2010;28:992-9.

22. Copello GJ, Teves S, Degrossi J, D’Aquino M, Desimone MF, Diaz LE. Antimicrobial activity on glass materials subject to disinfectant xerogel coating. J Ind Microbiol Biotechnol 2006;33:343-8.

23. Bosetti M,MassèA,Tobin E, Cannas M. Silver coated materials for external fixation devices: in vitro biocompatibility and genotoxicity. Biomaterials 2002;23:887-92.
24. Nablo BJ, Prichard HL, Butler RD, Klitzman B, Schoenfisch MH. Inhibition of implant-associated infections via nitric oxide release. Biomaterials 2005;26:6984-90.

25. Chung CJ, Lin HI, Tsou HK, Shi ZY, He JL. An antimicrobial TiO2 coating for reducing hospital-acquired infection.J Biomed Mater Res B Appl Biomater 2008;85:220-4.

26. Ainslie KM, Tao SL, Popat KC, Daniels H, Hardev V, Grimes CA, Desai TA. In vitro inflammatory response of nanostructured titania, silicon oxide, and polycaprolactone.J Biomed Mater Res A 2009;91:647-55.

27. Etienne O, Picart C, Taddei C, Haikel Y, Dimarcq JL, Schaaf P, Voegel JC, Ogier JA, Egles C. Multilayer polyelectrolyte films functionalized by insertion of defensin: a new approach to protection of implants from bacterial colonization. Antimicrob Agents Chemother 2004;48:3662-9.

28. Schrand AM, Huang H, Carlson C, Schlager JJ, Omacr Sawa E, Hussain SM, Dai L.Are diamond nanoparticles cytotoxic? J Phys Chem B 2007; I I :2-7.

29. Huang $\mathrm{H}$, Pierstorff E, Osawa E, Ho D. Protein-mediated assembly of nanodiamond hydrogels into a biocompatible and biofunctional multilayer nanofilm. ACS Nano 2008;2:203-I2.

30. Rauschmann MA, Wichelhaus TA, Stirnal V, Dingeldein E, Zichner L, Schnettler R, Alt V. Nanocrystalline hydroxyapatite and calcium sulphate as biodegradable composite carrier material for local delivery of antibiotics in bone infections. Biomaterials 2005;26:2677-84.

3I. Adams CS, Antoci V Jr, Harrison G, Patal P, Freeman TA, Shapiro IM, Parvizi J, Hickok NJ, Radin S, Ducheyne P. Controlled release of vancomycin from thin sol-gel films on implant surfaces successfully controls osteomyelitis.J Orthop Res 2009;27:701-9.

32. Kim HW, Kim HE, Salih V. Stimulation of osteoblast responses to biomimetic nanocomposites of gelatin-hydroxyapatite for tissue engineering scaffolds. Biomaterials 2005;26:5221-30.

33. Dzenis Y. Material science. Spinning continuous fibers for nanotechnology. Science 2004;304:1917-9.

34. Fu S, Yang L, Fan J, Wen Q, Lin S, Wang B, Chen L, Meng X, Chen Y, $\mathrm{Wu} \mathrm{J}$. In vitro mineralization of hydroxyapatite on electrospun poly ( $\varepsilon$-caprolactone)-poly (ethylene glycol)-poly( $\varepsilon$-caprolactone) fibrous scaffolds for tissue engineering application. Colloids Surf B Biointerfaces 2013;107:167-73.

35. Kikuchi M, Ikoma T, Matsumoto HN, Takakuda K, Shinomiya K, Tanaka J. Biomimetic synthesis of bone-like nanocomposites using the self-organization mechanism of hydroxyapatite and collagen. Compos SciTechnol 2004;64:8I 9-25.

36. Woo KM, Chen VJ, Ma PX. Nano-fibrous scaffolding architecture selectively enhances protein adsorption contributing to cell attachment.J Biomed Mater Res A 2003;67:53I-7.

37. Langer R, Tirrell DA. Designing materials for biology and medicine. Nature 2004;428:487-92

38. Williams JM,Adewunmi A, Schek RM, Flanagan CL, Krebsbach PH, Feinberg SE, Hollister SJ, Das S. Bone tissue engineering using polycaprolactone scaffolds fabricated via selective laser sintering. Biomaterials 2005;26:48I7-27.

39. Jaiswal AK, Dhumal RV, Ghosh S, Chaudhari P, Nemani H, SoniVP, Vanage GR, Bellare JR. Bone healing evaluation of nanofibrous composite scaffolds in rat calvarial defects: a comparative study.J Biomed Nanotechnol 20I3;9:2073-85.

40. Xing H, Komasa S, TaguchiY, SekinoT, Okazaki J. Osteogenic activity of titanium surfaces with nanonetwork structures. Int J Nanomedicine 20|4;9:| 74| -55.

4I. Frandsen CJ, Brammer KS, Noh K, Johnston G, Jin S. Tantalum coating on TiO2 nanotubes induces superior rate of matrix mineralization and osteofunctionality in human osteoblasts. Mater Sci Eng C Mater Biol Appl 20I4;37:332-4I.

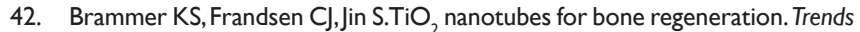
Biotechnol 2012;30:315-22

43. Li G, Bouxsein ML, Luppen C, Li XJ, Wood M, Seeherman HJ, Wozney JM, Simpson $\mathrm{H}$. Bone consolidation is enhanced by rhBMP-2 in a rabbit model of distraction osteogenesis. J Orthop Res 2002;20:779-88.

44. al Ruhaimi KA. Comparison of different distraction rates in the mandible: an experimental investigation. Int J Oral Maxillofac Surg 200I;30:220-7.

45. Zakhary K, Motakis D, Hamdy RH, Campisi P, Amar Y, Lessard ML. Effect of recombinant human bone morphogenetic protein 7 on bone density during distraction osteogenesis of the rabbit mandible.J Otolaryngol 2005;34:407-I4.

46. Wang Y, Ni M, Tang PF, Li G. Novel application of HA-TCP biomaterials in distraction osteogenesis shortened the lengthening time and promoted bone consolidation.J Orthop Res 2009;27:477-82.

47. $\mathrm{Li} \mathrm{G}$, Simpson AH, Triffitt JT. The role of chondrocytes in intramembranous and endochondral ossification during distraction osteogenesis in the rabbit. 
CalcifTissue Int 1999;64:310-7.

48. Woo BH, Fink BF, Page R, Schrier JA, Jo YW, Jiang G, DeLuca M, Vasconez HC, DeLuca PP. Enhancement of bone growth by sustained delivery of recombinant human bone morphogenetic protein-2 in a polymeric matrix. Pharm Res 200I; 18:1747-53.

49. Murphy WL, Peters MC, Kohn DH, Mooney DJ. Sustained release of vascular endothelial growth factor from mineralized poly (lactide-co-glycolide) scaffolds for tissue engineering. Biomaterials 2000;21:2521-7.

50. Haidar ZS,Tabrizian M, Hamdy RC.A hybrid rhOP-I delivery system enhances new bone regeneration and consolidation in a rabbit model of distraction osteogenesis. Growth Factors 2010;28:44-55.

5I. Konaș E, Emin Mavili M, Korkusuz P, Demir D, Oner F, Canter HI.Acceleration of distraction osteogenesis with drug-releasing distractor. J Craniofac Surg 2009;20:204I-8.

52. Urist MR, Mikulski A, Lietze A. Solubilized and insolubilized bone morphogenetic protein. Proc Natl Acad Sci U SA 1979;76: 1828-32.

53. Felemovicius J, Ortiz Monasterio F, Gomez Radillo LS, Serna A. Determining the optimal time for consolidation after distraction osteogenesis.J Craniofac Surg 2000; I I:430-6.

54. Mofid MM, Inoue N, Atabey A, Marti G, Chao EY, Manson PN Vander Kolk CA. Callus stimulation in distraction osteogenesis. Plast Reconstr Surg 2002; 109:1621-9.

55. Takamine Y, Tsuchiya H, Kitakoji T, Kurita K, Ono Y, Ohshima Y, Kitoh H, Ishiguro N, Iwata $\mathrm{H}$. Distraction osteogenesis enhanced by osteoblastlike cells and collagen gel. Clin Orthop Relat Res 2002;(399):240-6.

56. Okazaki H, Kurokawa T, Nakamura K, Matsushita T, Mamada K, Kawaguchi H. Stimulation of bone formation by recombinant fibroblast growth factor- 2 in callotasis bone lengthening of rabbits. CalcifTissue Int 1999;64:542-6.

57. Wang H, Li X, Tomin E, Doty SB, Lane JM, Carney DH, Ryaby JT. Thrombin peptide (TP508) promotes fracture repair by up-regulating inflammatory mediators, early growth factors, and increasing angiogenesis. J Orthop Res 2005;23:67I-9.

58. Vallet-Regí M, Ruiz-González L, Izquierdo-Barba I. Revisiting silica based ordered mesoporous materials: medical applications. J Mater Chem 2006;|6:26-3|.

59. Vallet-Regí M. Ordered mesoporous materials in the context of drug delivery systems and bone tissue engineering. Chemistry 2006; I 2:5934-43.

60. Jain RA.The manufacturing techniques of various drug loaded biodegradable poly (lactide-co-glycolide) (PLGA) devices. Biomaterials 2000;21:2475-90.

61. Shive MS, Anderson JM. Biodegradation and biocompatibility of PLA and PLGA microspheres. Adv Drug Deliv Rev 1997;28:5-24.

How to cite this article: Singleton AE, Ver Halen JP. Nanotechnology applications in osteodistraction. Plast Aesthet Res 2014;1:5-12.

Source of Support: Nil, Conflict of Interest: None declared.

Received: 21-03-2014; Accepted: 29-05-2014 